\title{
A Novel fast Fourier Transform Square Wave Voltammetry for Determination of Sulfabenzamide at $\mathrm{Er}_{2}\left(\mathrm{WO}_{4}\right)_{3} / \mathrm{CP}$ Electrode
}

\author{
Hana Beigizadeh ${ }^{1}$, Mohammad Reza Ganjali $^{1,2, *}$, Parviz Norouzi $^{1,2}$ \\ ${ }^{1}$ Center of Excellence in Electrochemistry, School of Chemistry, University of Tehran, \\ Tehran, Iran \\ ${ }^{2}$ Biosensor Research Center, Endocrinology \& Metabolism Molecular-Cellular Sciences Institute, \\ Tehran University of Medical Sciences, Tehran, Iran \\ *E-mail: ganjali@khayam.ut.ac.ir
}

doi: $10.20964 / 2018.11 .35$

Received: 29 July 2018 / Accepted: 7 September 2018 / Published: 1 October 2018

In this study, a novel sensitive sulfabenzamide voltammetric sensor has been developed for use through fast Fourier transform square wave voltammetry (FFTSWV). This is achieved through the modification of a carbon paste electrode with Erbium(III) tungstate nanoparticles $\left(\mathrm{Er}_{2}\left(\mathrm{WO}_{4}\right)_{3} \mathrm{NPs}\right)$. The cyclic voltammogram of the analyte contained an irreversible oxidation peak at around $0.92 \mathrm{~V} v s$. $\mathrm{Ag} / \mathrm{AgCl}$, which was used for the measurements. To achieve higher sensitivity, the effects of parameters such as, $\mathrm{pH}$, quantity of the nanoparticles used, amplitude and frequency were also optimized. As a result, an optimal linear concentration range of $1.0 \times 10^{-6}-250.0 \times 10^{-6} \mathrm{M}$ with a limit of detection $0.45 \times 10^{-7} \mathrm{M}$ was reached. Characterization techniques such as transmission electron microscopy (TEM), and X-ray powder diffraction (XRD) were also used to study the size and morphology of the $\mathrm{Er}_{2}\left(\mathrm{WO}_{4}\right)_{3}$ NPs. The sensor responses proved to have a good reproducibility and repeatability with acceptable RSD levels of $(5.6 \%, 1.79 \%$ respectively), in addition to the long-term stability of almost one month.

Keywords: Sulfonamide, Carbon paste electrode, $\mathrm{Er}_{2}\left(\mathrm{WO}_{4}\right)_{3}$ nanoparticles, Fast Fourier transform Square wave voltammetry

\section{$\underline{\text { FULL TEXT }}$}

(C) 2018 The Authors. Published by ESG (www.electrochemsci.org). This article is an open access article distributed under the terms and conditions of the Creative Commons Attribution license (http://creativecommons.org/licenses/by/4.0/). 